\title{
Prostatic carcinoma presenting with respiratory symptoms: response to orchidectomy
}

\author{
FG SIMPSON, HA KING, P WHELAN, NJ COOKE
}

From the Department of Respiratory Medicine, General Infirmary, and the Department of Urology, St James's Hospital, Leeds

Pulmonary lymphangitis carcinomatosa carries a poor prognosis.' We report a case of prostatic carcinoma in a patient who presented with respiratory symptoms only. The diagnosis of lymphangitis carcinomatosa was made by transbronchial lung biopsy. Symptoms, results of respiratory function tests, and radiological appearances all improved considerably after orchidectomy.

\section{Case report}

A 68 year old man, a non-smoker, presented in May 1983 with a four week history of increasing dyspnoea on exertion and weight loss of $3 \mathbf{~ k g}$. He denied any urinary symptoms. There was no lymphadenopathy and the chest was clinically clear. Rectal examination revealed an enlarged hard prostate with lateral extension on the right. A chest radiograph (fig 1) showed diffuse reticular shadowing sug-

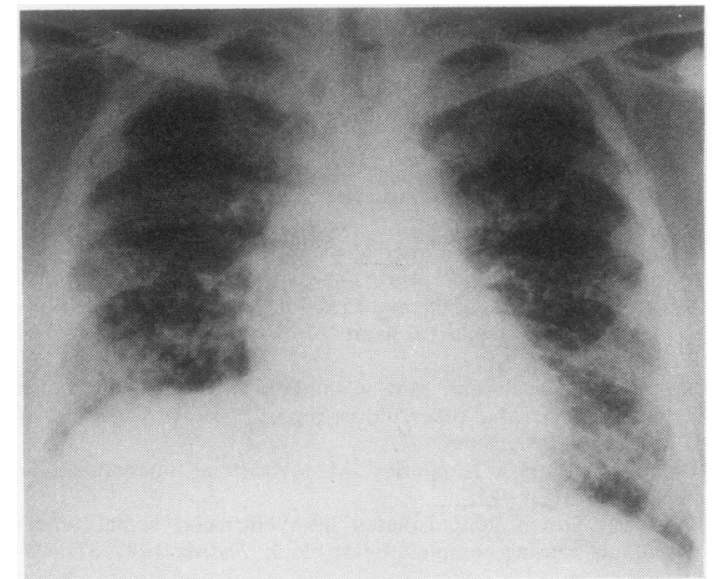

Fig 1 Chest radiograph showing widespread reticular shadowing due to lymphangitis carcinomatosa

Address for reprint requests: Dr FG Simpson, General Infirmary, Leeds LS1 3EX.

Accepted 24 March 1984 gestive of interstitial lung disease. The serum acid phos- $ं$ phatase was $48.4 \mathrm{U} / 1$ (normal range $0-4 \mathrm{U} / 1$ ). Respiratory $\mathrm{N}$ function tests showed a restrictive pattern (table).

At bronchoscopy the mucosa was reddened but no endobronchial lesion was seen. Transbronchial biopsy showed aggregates of small polyhedral cells thought to be well differentiated adenocarcinoma with invasion of subpleural lymphatics (fig 2). Trucut perineal biopsy of the prostate yielded material which showed invasive well differentiated adenocarcinoma. An isotope bone scan showed multiple bone metastases. Bilateral subcapsular orchidectomy was performed.

The patient's shortness of breath improved dramatically over the next four months. Serum acid phosphatase activity fell to $11.4 \mathrm{U} / \mathrm{l}$. The chest radiograph showed complete clearing of the widespread shadowing. Lung volumes and transfer factor were almost normal four months after orchidectomy and the patient remains well eight months after operation.

\section{Discussion}

Pulmonary metastases are found frequently at necropsy in patients dying of prostatic carcinoma but are diagnosed rarely in life and seldom produce symptoms. ${ }^{2}$ Discrete lesions, lymphangitis carcinomatosa, pleural effusions, ${ }^{34}$

Table Lung function values before and after orchidectomy

\begin{tabular}{|c|c|c|c|}
\hline & Predicted & $\begin{array}{l}\text { Before } \\
\text { orchidectomy }\end{array}$ & $\begin{array}{l}4 m \text { after } \\
\text { orchidectomy }\end{array}$ \\
\hline \multirow[t]{2}{*}{ 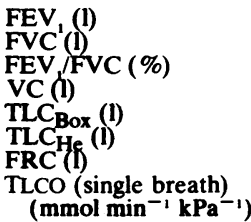 } & $\begin{array}{c}1.90 \\
2.86 \\
66 \\
2.86 \\
4.85 \\
4.85 \\
2.94\end{array}$ & $\begin{array}{c}1.47 \\
1.96 \\
75 \\
2.02 \\
3.57 \\
3.42 \\
2.64\end{array}$ & $\begin{array}{c}1.97 \\
2.57 \\
76 \\
2.57 \\
4.20 \\
4.42 \\
2.99\end{array}$ \\
\hline & & $5 \cdot 37$ & 6.07 \\
\hline
\end{tabular}

FVC-forced vital capacity; VC-vital capacity; TLC-total lung 0 capacity; TLC $\mathrm{B}_{\mathrm{Box}}$ - TLC measured by body plethysmograph; TLC $_{\mathrm{He}}$ - TLC measured by helium dilution; FRC-functional residual capacity; TLCO-transfer factor for carbon monoxide.

Conversion: SI to traditional units: $1 \mathrm{mmol} \mathrm{min}^{-1} \mathrm{kPa}^{-1}=2.99 \mathrm{ml}$ $\min ^{-1}$. 


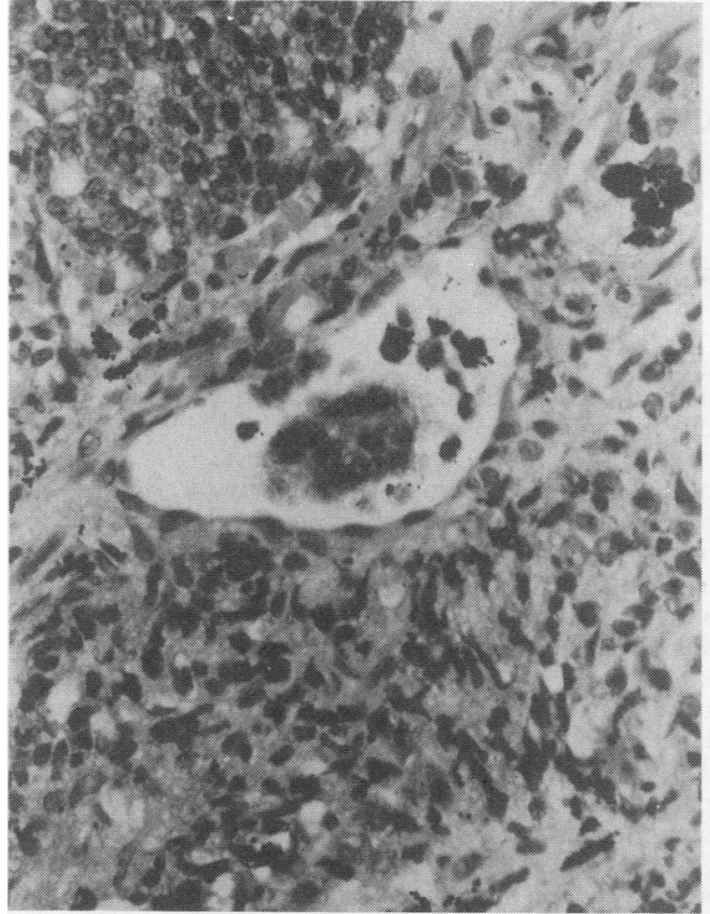

Fig 2 Transbronchial lung biopsy specimen showing malignant cells in a subpleural lymphatic $(\times 62)$.

and pulmonary hypertension ${ }^{5}$ have all been reported. Respiratory symptoms have been reported in some patients with prostatic carcinoma ${ }^{2-7}$ but in all of these cases urological symptoms, ${ }^{2467}$ symptomatic bone metastases, ${ }^{35}$ or widespread lymphadenopathy ${ }^{7}$ were present before respiratory symptoms became prominent. In the patients with histological confirmation of pulmonary disease tissue was obtained either at postmortem examination or at open lung biopsy. Positive transbronchial biopsy findings have not been reported. Endocrine manipulation has resulted in improvement of symptoms, radiological appearances, and arterial oxygen tension in some patients; ${ }^{2367}$ but demonstration of a restrictive pattern of results in pulmonary function tests with improvement after treatment has not to our knowledge been recorded.

Rectal examination and estimation of serum acid phosphatase should be routine in the investigation of men with suspected pulmonary lymphangitis carcinomatosa and biopsy of the prostate should be considered. Treatment of this condition may be unexpectedly rewarding.

We thank Dr GJ Hardy of the Department of Pathology, St James's University Hospital, Leeds, for the photomicrographs and Mrs K Marsden for secretarial assistance.

\section{References}

' Harold JT. Lymphangitis carcinomatosa of the lung. QJ Med 1952;21:353-9.

${ }^{2}$ Bolton BH. Pulmonary metastases from carcinoma of the prostate: incidence and case report of a long remission. J Urol 1965;94:73-7.

${ }^{3}$ Heffner JE, Duffey DJ, Schwarz MI. Massive pleural effusions from prostatic lymphangitis carcinomatosis. Resolution with endocrine therapy. Arch Intern Med 1982;142:375-6.

4 Kwart AM, Sims JE. Blood vascular invasion: a poor prognostic factor in adenocarcinoma of the prostate. $J$ Urol 1978;119: $138-40$.

${ }^{5}$ Keeping IM, Buchanan R, Dodds JH. Microscopic tumour emboli from carcinoma of the prostate. $\mathrm{Br} J$ Dis Chest 1982;76:298-300.

- Schwarz MI, Waddell LC, Dombeck DH, Weill H, Ziskind MM. Prolonged survival in lymphangitis carcinomatosis. Ann Intern Med 1969;71:779-83.

' Lome LG, John T. Pulmonary manifestations of prostatic carcinoma. J Urol 1973; 109:680-5. 